\title{
Experimental investigation on the torsion-shear interaction between stone blocks in frictional contact
}

\author{
C. Casapulla \& F. Portioli \\ Department of Structures for Engineering and Architecture, \\ University of Naples Federico II, Italy
}

\begin{abstract}
The definition of the yield domains within limit analysis of 3D dry-jointed masonry block structures requires experimental and analytical investigation on the frictional contact problems. In this paper the torsion-shear interaction is experimentally investigated with reference to the single contact interface of a stack of two dry-jointed tuff blocks. A number of tests based on different eccentricities and directions of the horizontal loading are carried out in order to consider interactions between shear and torsion moment. The results are compared with those obtained by the analytical model of two overlapped rigid blocks, based on the assumptions of infinite compressive strength for blocks and no-tension and frictional behaviour at their contact. In particular, the non-linear yield function in torsion-shear interaction is piecewise linearized in order to provide a simplified and conservative expression for inclusion in linear programming (LP) formulations.

Keywords: experimental frictional behaviour, limit state analysis, torsion-shear interaction effects, non-linear yield criteria.
\end{abstract}

\section{Introduction}

The application of rigid block limit analysis to masonry structures has received a growing attention from researchers in the last decades [1-10]. Of particular 
interest are the formulations of the problem in terms of mathematical programming [11-16]. Within these approaches the blocks are treated as nodes and the interfaces as elements of a conventional finite element discretization (discrete element modelling). Failure modes are defined as sets of relative displacements among blocks at their contact interfaces and, when the blocks are assumed to possess infinite compressive strength, they generally involve separation, rocking, sliding and twisting of the interfaces, and combinations of them. Cracking, crushing or deformation of the elements are generally ignored, unless different material models for rigid-body elements are considered [17].

Crucial to the model formulation is a proper description of the constitutive laws that govern the contact behaviour. For a generic contact interface, a set of yield conditions delineating contact failure can be defined in the space of the static variables, in direct analogy to plasticity, as the failure modes behave in essentially a rigid perfectly-plastic manner [18-20]. When using a convex contact formulation [21], a single point located at the centre of each interface is used to model interactions among rigid blocks. The stress resultant vector has six components, including normal and shear forces as well as bending and torsion moments, corresponding in a virtual work sense to the internal degrees of freedom of the contact interface.

However, the definition of the yield domains and their interactions to properly describe potential three-dimensional responses of dry assemblages of rigid blocks still represents a hard task, as the modelling of the real behaviour of frictional contact interfaces under simultaneous shear forces, torsion and bending moments is a topic still poorly studied $[1,9,14,22]$, especially from the experimental point of view. In fact, several test methods to determine the shear strength of masonry joints were investigated [23, 24], but only addressing the definition of the initial shear strength, for which the Coulomb's law was considered the most adequate in practice. The triplet test was then adopted as the standard test in Europe [25], while no standard tests are available for torsion-shear-bending moment interactions.

As a first attempt to fill such a gap of information, an experimental investigation on different $3 \mathrm{D}$ yield domains and their interactions was presented in $[26,27]$, with reference to the single contact interface of a system composed of two dry-jointed tuff blocks. The testing device was designed and realized ad hoc and several sets of tests were carried out, considering different eccentricities of the vertical and horizontal loading implying interactions among shear, torsion and bending moments.

This paper represents an interesting focus on some issues of this experimental campaign, regarding the torsion-shear interaction between blocks. The experimental results are compared with those obtained by the analytical model of two overlapped rigid blocks, under the assumptions of infinite compressive strength for blocks and no-tension and frictional behaviour at their contact. In particular, piecewise linearizations are proposed to treat the non-linear yield function in torsion-shear interaction, in order to be included in a limit analysis formulation. Within mathematical programming, the linearization of yield functions is necessary to reduce the limit analysis problem to a linear program. 


\section{Experimental investigation}

A series of experimental tests were presented in $[26,27]$ to investigate the $3 \mathrm{D}$ frictional behaviour of dry masonry joints. This paper is focused on the results for torsion-shear interaction.

Specimens were made of stacks formed of two dry-jointed tuff blocks with dimensions of $300 \times 200 \times 100 \mathrm{~mm}$ and weight of $75 \mathrm{~N}$ each. The units were previously sawn in mechanical cutting. Different combinations of horizontal forces were considered to simulate yield conditions of torsion-shear interaction.

\subsection{Test setup}

The test setup was designed and realized ad hoc and consists of a stack of two tuff blocks positioned on the supporting plate of a universal electromechanical testing machine (Galdabini SUN 5) which was used to apply variable loads (fig. 1).

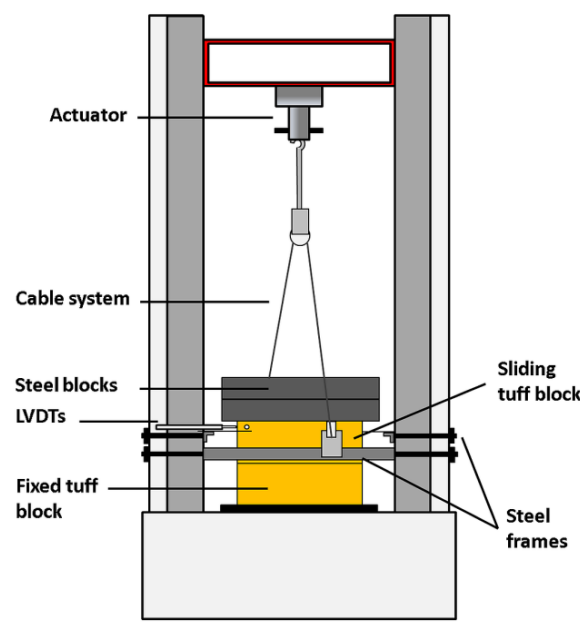

(a)

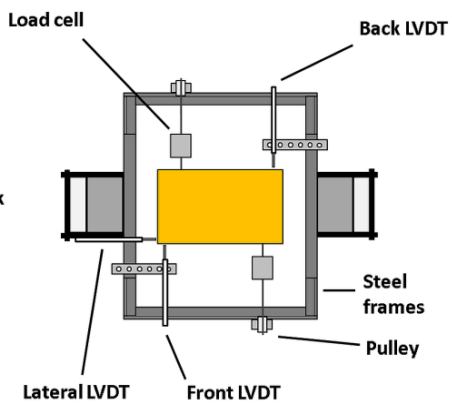

(b)

Figure 1: Test setup. (a) Front view, (b) plan view.

The block at the base was fixed at the testing machine whereas the upper block was subjected to vertical and horizontal loads. The constant vertical load was applied using two steel blocks with dimensions of $360 \times 135 \times 60 \mathrm{~mm}$ and weight of $196 \mathrm{~N}$ each. To activate the failure mechanism at the dry joint interface, monotonically increasing horizontal forces were applied using the testing machine on the side faces of the upper block.

A steel cable supported by a system of small pulleys and a steel frame was connected to the actuator of the testing machine running in the vertical direction to apply the load on the tuff block along the horizontal plane. The load was applied under displacement control at a constant rate of $10 \mathrm{~mm} / \mathrm{min}$, using the control system of the testing machine to calibrate the speed of the vertical actuator. 
The forces were measured using two load cells with a maximum capacity of $500 \mathrm{~N}$ and an acquisition frequency of $10 \mathrm{~Hz}$, positioned between the cable and the tuff block. The displacements were measured using three Linear Variable Displacement Transducers (LVDT) with a displacement range of $\pm 50 \mathrm{~mm}$ supported by the steel frame. The LVDTs were positioned at the edges of the blocks in order to detect the activation of failure mechanism and measure three independent components of displacements to obtain the translation and rotation of the sliding block. The load cells and the transducers were connected to a digital scanner to acquire forces and displacements.

\subsection{Experimental results}

Fig. 2 shows the two overlapped blocks and their bed joint referred to axes $X, Y$ and $Z$ of the standard Cartesian coordinate system in three dimensions. The block dimensions $a \times b \times h$ are $300 \times 200 \times 100 \mathrm{~mm}$, the normal force on the bed joint is given by the sum of the weight of the upper block $(Q=75 \mathrm{~N})$ and the overload $(P=392 \mathrm{~N})$ centrally applied on the top. The horizontal loading is represented by the shear force $V$ applied at variable eccentricity and direction in the midplane of the upper block.

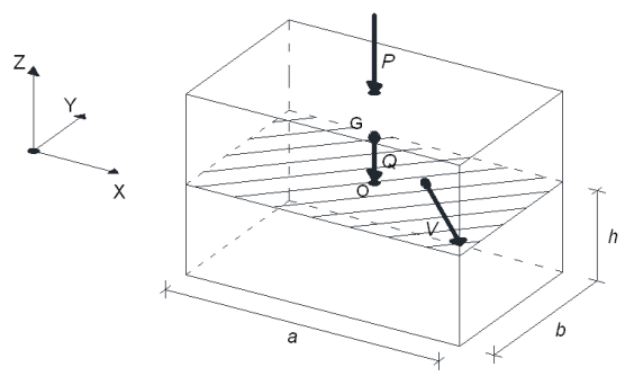

Figure 2: Vertical and horizontal loading on the tested specimen of two overlapped blocks.

The different horizontal load conditions considered to define the torsion-shear interaction are represented in fig. 3 with reference to the $X Y$-plane of the bed joint. Each case was investigated by a number of five tests and all the cases are gathered in two groups of sets.

The first group includes the cases of the shear force parallel to the $Y$-axis and applied at two different points, say $0.25 \mathrm{a}$ and $0.45 \mathrm{a}$ for Set 1 and Set 2, respectively. The second group is referred to the shear force inclined by an angle of $\pm 45^{\circ}$ to the same axis and applied at the same different points (Sets 3-6). Some samples of these groups are illustrated in fig. 4.

In fig. 5 one of the five tests of Set 2 is plotted in terms of load-displacement curves. The horizontal force registered by the load cell was combined with the displacements registered both by the back LVDT (red continuous line) and by the front LVDT (blue dotted line) in $Y$-direction, taking into account that the former transducer works in tension while the latter in compression. 


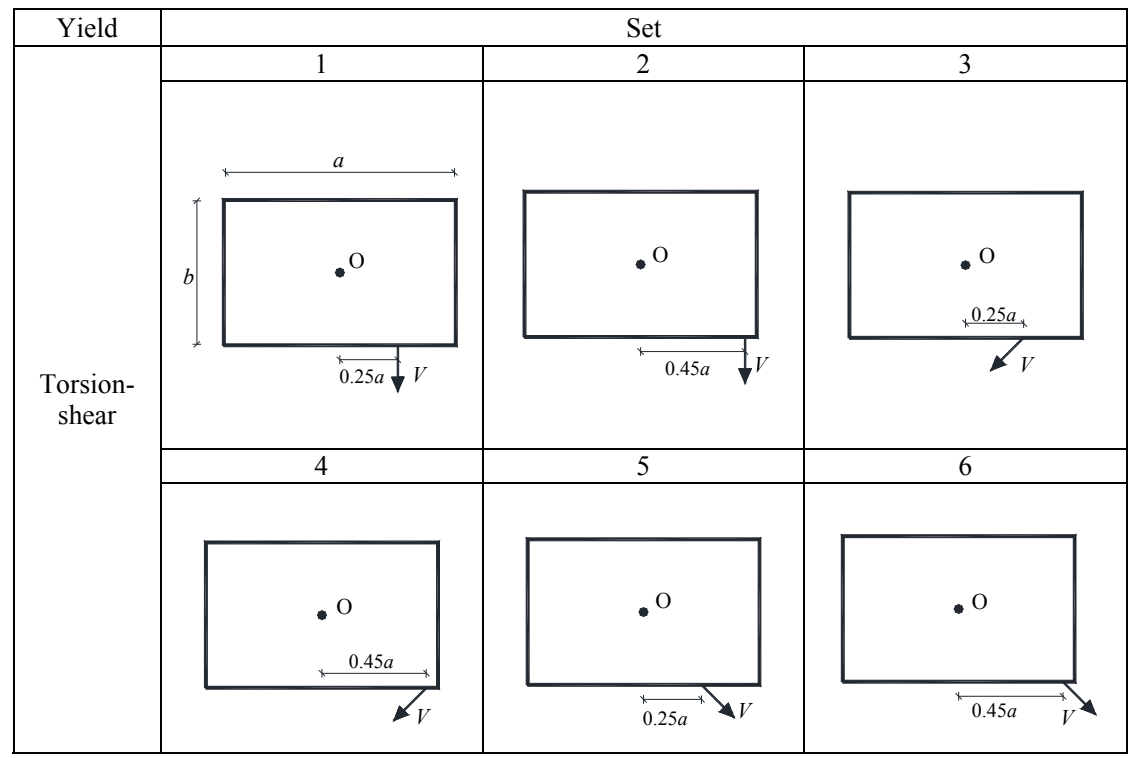

Figure 3: Experimental series for torsion-shear interaction on the frictional bed joint. Sets 1-6.

As expected, the signals registered by both LVDTs are almost coincident for the first vertical branch, which represents the rigid behaviour of the block interface. The maximum value occurring at the first noticeable movement can be considered as the reference limiting shear force $V$. The displacements registered after this point show the stick-slip behaviour which is typical of frictional sliding [28]. Also, it is worth noting that the enhancement of displacement occurred with a slight increasing of the loading force. This effect is not physical, but can be explained by a kinematical point of view, as it is related to the large displacements experienced by the tested block [27].

However, the most interesting remark is that the displacements at the back LVDT were greater than those at the front one because the centre of torsion is expected to be on the opposite side with respect to the $Y Z$-midplane of the block and, hence, closer to the front LVDT. This is consistent with the motion of the block which is characterized by a rotation about a centre away from the centre of gravity, as well described by Casapulla [1].

The experimental results are reported in Table 1 in terms of the limiting shear force $V$ (mean, minimum and maximum values) and the coefficient of variation. $V$ and $M_{\mathrm{T}}$ are represented by their absolute values and $M_{\mathrm{T}}$ is referred to the moment of $V$ around point $\mathrm{O}$.

In this table it is evident that increasing the eccentricity, the torsion moment will increase and the shear force decreases. The variability of the results is relatively low, with a coefficient of variation ranging from $2.7 \%$ up to $6 \%$. 

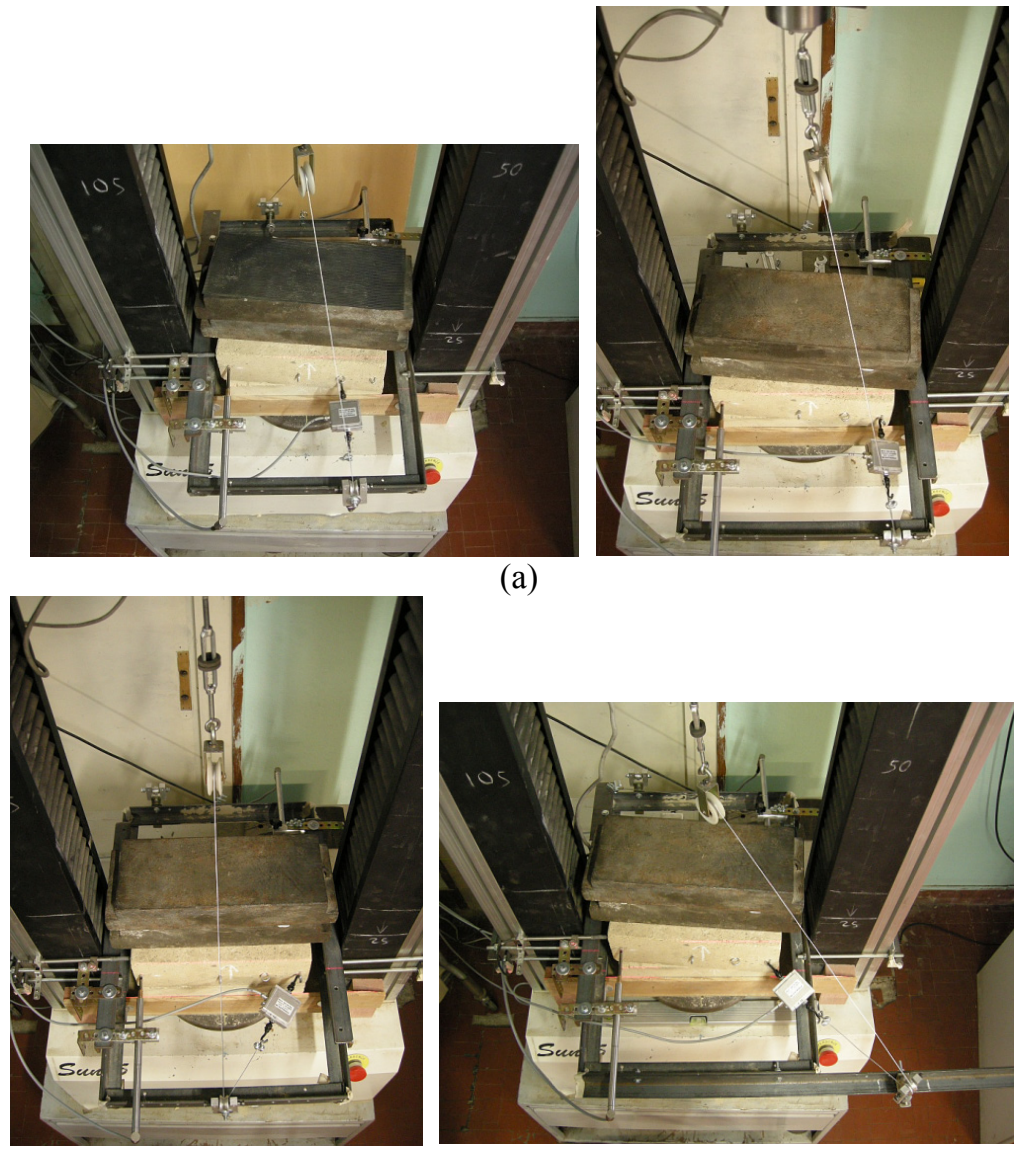

(a)

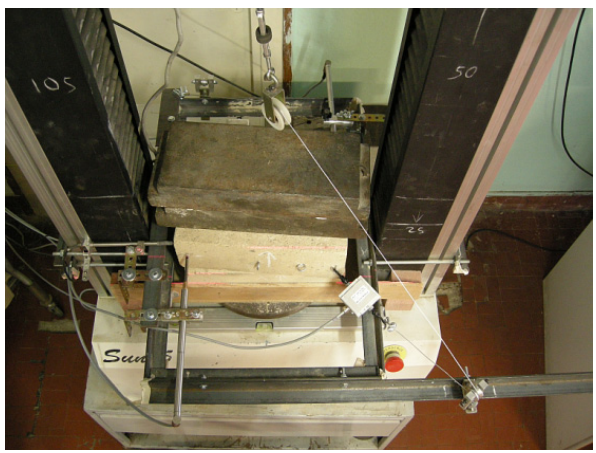

(b)

Figure 4: Sample under eccentric horizontal force (a) parallel to the $\mathrm{Y}$-axis and (b) inclined of $\pm 45^{\circ}$.

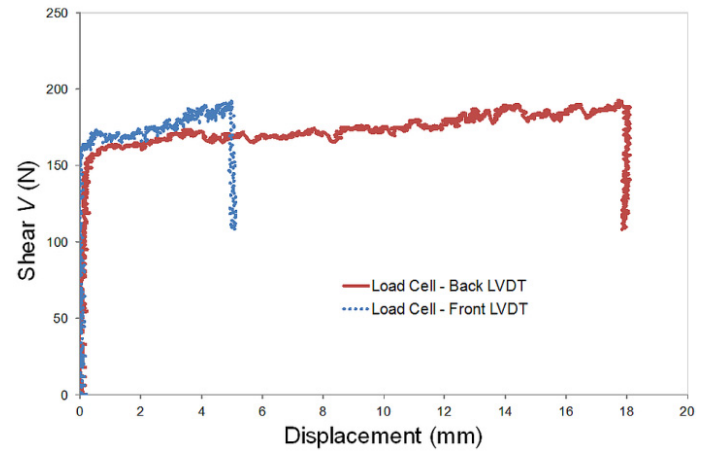

Figure 5: Torsion-shear test (Set 2). Load-displacement curves. 
Table 1: Experimental torsion-shear interaction.

\begin{tabular}{|c|c|c|c|c|c|}
\hline & $\begin{array}{c}\text { Mean } V \\
(\mathrm{~N})\end{array}$ & $\begin{array}{c}\text { Mean } M_{\mathrm{T}} \\
(\mathrm{Nm})\end{array}$ & $\mathrm{CV}(\%)$ & $\operatorname{Min} V(\mathrm{~N})$ & $\operatorname{Max} V(\mathrm{~N})$ \\
\hline Set 1 & 216 & 16 & 2.7 & 209 & 225 \\
\hline Set 2 & 166 & 22 & 3.2 & 160 & 172 \\
\hline Set 3 & 176 & 22 & 3.6 & 169 & 183 \\
\hline Set 4 & 147 & 24 & 5.8 & 136 & 157 \\
\hline Set 5 & 294 & 5 & 6.0 & 278 & 324 \\
\hline Set 6 & 285 & 7 & 5.2 & 265 & 303 \\
\hline
\end{tabular}

\section{Theoretical vs. experimental strength}

The experimental results are compared with existing formulations for torsionshear interaction between stone blocks $[1,14,15]$.

A rigid-plastic model is adopted, where the blocks are considered infinitely strong in compression, tension and shear so that no crushing/cracking and no deformation can take place. Also, no-tension behaviour and infinite compressive strength are assumed for the frictional contact.

Both shear force and torsion moment strengths of an interface are provided by shear stresses. When the contact interface is only subjected to a centred compressive force $N$ and to a torsion moment $M_{\mathrm{T}}$, the centroid of the interface is coincident with the centre of plastic torsion and the direction of the shear stress vector at each point is perpendicular to its distance from this centre and parallel to the relative tangential flow, according to Coulomb's law.

When the contact interface is subjected to torsion moment and shear force, the centre of plastic torsion is away from the centroid of the interface, but the shear stress vectors at each point are still orthogonal to their distance from this centre.

For this case, a non-linear formulation and a conservative linear approximation can be derived according to Casapulla [1], as represented in fig. 6. The linear approximation, also used by Portioli et al. [15], can be expressed by the relation:

$$
y^{t s}=\left|M_{\mathrm{T}}\right|-M_{\mathrm{T} 0}\left(1-\frac{V}{V_{0}}\right) \leq 0
$$

where:

$$
M_{\mathrm{T} 0}=V_{0} c_{\mathrm{T}} \quad V_{0}=\mu N
$$

being $c_{\mathrm{T}}$ the torsion constant and $\mu=0.64$ the value of the experimental friction coefficient.

In order to be compared, experimental data are reported on the theoretical yield domain (fig. 6), while all the results are collected in Table 2.

The column called "Non-linear" reports the results numerically obtained by the analytical formulation presented and described in [1, 15], while the results obtained by using the "Linear" yield domain were referred to eqn (1). 


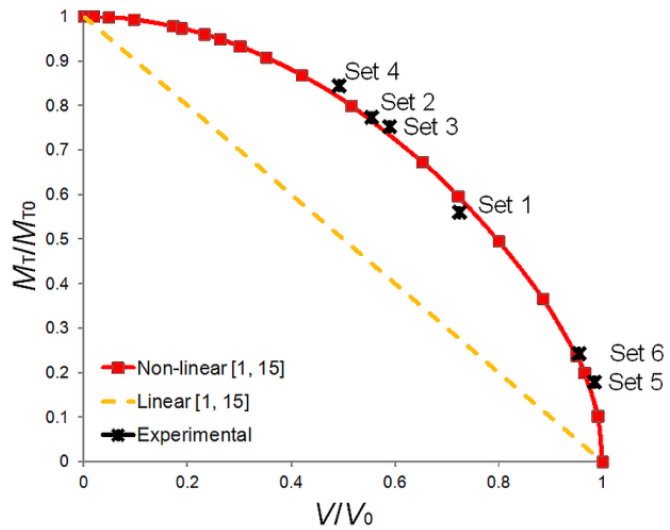

Figure 6: Theoretical curves with experimental results.

Table 2: Comparison of experimental and existing numerical models.

\begin{tabular}{|c|c|c|c|c|c|}
\hline \multirow{2}{*}{ Yield } & Set & $\begin{array}{c}\text { Exp } \\
V(\mathrm{~N})\end{array}$ & $\begin{array}{c}\text { Non-linear } \\
V(\mathrm{~N})\end{array}$ & $\begin{array}{c}\text { Linear } \\
V(\mathrm{~N})\end{array}$ & $\begin{array}{c}\text { Diff. Linear } \\
\text { vs. exp. (\%) }\end{array}$ \\
\hline \multirow{4}{*}{ Torsion-shear } & 1 & 216 & 216 & 168 & -22.1 \\
\cline { 2 - 6 } & 2 & 166 & 162 & 125 & -24.7 \\
\cline { 2 - 6 } & 3 & 176 & 174 & 131 & -25.5 \\
\cline { 2 - 6 } & 4 & 147 & 144 & 110 & -25.2 \\
\cline { 2 - 6 } & 5 & 294 & 291 & 253 & -14.1 \\
\cline { 2 - 6 } & 6 & 285 & 284 & 238 & -16.5 \\
\hline Average error & All sets & - & - & - & -21.4 \\
\hline
\end{tabular}

The comparisons of the results obtained by the theoretical model against experimental evidence show that the "Non-linear" yield domain is in perfect agreement with the observed experimental results, while the "Linear" values are significantly lower than them.

The percentage difference between experimental and predicted shear forces by using the linear relationship was found to be relatively large, i.e. up to $25.5 \%$, with an average error of about $21.4 \%$, even if in favour of safety.

This expectable discrepancy is due to the fact that the linear approximation is too conservative with respect to the non-linear strength, as also evident in fig. 6 . A piecewise linearization of the non-linear curve is therefore necessary to reduce the differences observed.

\subsection{The proposed yield function}

Other than the linearized condition proposed by Casapulla [1] and used by Portioli et al. [15], another approximation can be found in the literature, as the "Threelinear" piecewise function proposed by Orduña and Lourenço [14], illustrated in fig. 7. 


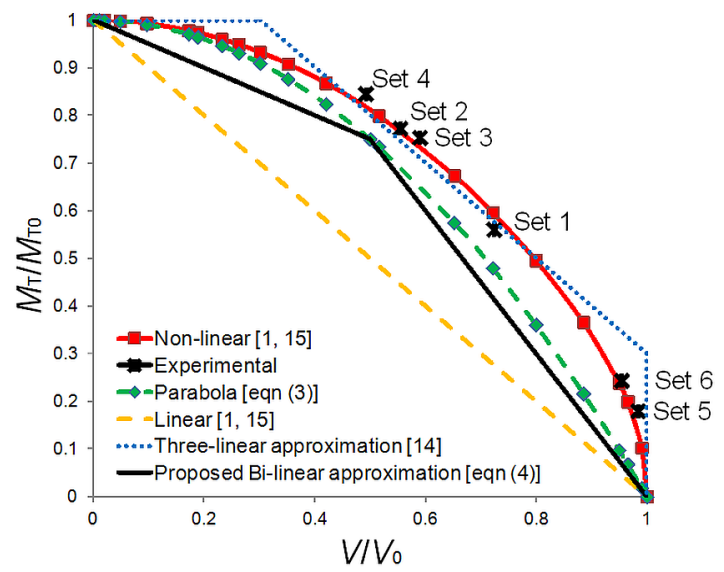

Figure 7: Proposed torsion-shear interaction domain.

However, in order to find a more conservative approximation, the parabolic curve reported in the same figure is considered, expressed by:

$$
y^{t s}=\left|M_{\mathrm{T}}\right|-M_{\mathrm{T} 0}\left(1-\frac{V^{2}}{V_{0}^{2}}\right) \leq 0
$$

and a piecewise linearization of this curve is proposed. The two branches are represented by the following yield functions:

$$
\begin{aligned}
& y_{1}^{t s}=\left|M_{\mathrm{T}}\right|+0.5 c_{\mathrm{T}}|V|-M_{\mathrm{T} 0} \leq 0 \\
& y_{2}^{t s}=\left|M_{\mathrm{T}}\right|+1.5 c_{\mathrm{T}}|V|-1.5 M_{\mathrm{T} 0} \leq 0
\end{aligned}
$$

In Table 3 the new results obtained by using the "Parabola" yield domain of eqn (3) and the "Bi-linear" one of eqn (4) are compared with experimental results.

Table 3: Comparison of experimental and proposed numerical models.

\begin{tabular}{|c|c|c|c|c|c|}
\hline \multirow{2}{*}{ Yield } & Set & $\begin{array}{c}\text { Exp } \\
V(\mathrm{~N})\end{array}$ & $\begin{array}{c}\text { Parabola } \\
V(\mathrm{~N})\end{array}$ & $\begin{array}{c}\text { Bi-linear } \\
V(\mathrm{~N})\end{array}$ & $\begin{array}{c}\text { Diff. Bi-linear } \\
\text { vs. exp. (\%) }\end{array}$ \\
\hline \multirow{7}{*}{ Torsion-shear } & 1 & 216 & 205 & 197 & -8.9 \\
\cline { 2 - 6 } & 2 & 166 & 156 & 155 & -6.5 \\
\cline { 2 - 6 } & 3 & 176 & 164 & 161 & -8.4 \\
\cline { 2 - 7 } & 4 & 147 & 137 & 135 & -8.3 \\
\cline { 2 - 7 } & 6 & 294 & 273 & 266 & -9.4 \\
\hline Average error & All sets & - & - & - & -10.5 \\
\hline
\end{tabular}


The $\%$ difference between experimental and predicted shear forces by using the "Bi-linear" relationship was significantly reduced with respect to the previous one, i.e. up to $10.5 \%$, with an error of about $8.7 \%$, and, again, in favour of safety.

\section{Conclusions}

Limit analysis of systems formed from rigid-blocks in frictional contact should rely on a proper description of the yield domains at the interfaces.

This paper is focused on the experimental and analytical investigation of the torsion-shear interactions carried out within a more extensive experimental programme for yield domains. The specimens were made of stacks formed of two dry-jointed tuff blocks and the load was applied to the upper block, under displacement control at constant rate. The load-displacement curve shows the rigid-plastic behaviour of the frictional contact and the forces corresponding to the first displacement were considered as the reference resistances.

These results were compared with those obtained by the analytical model of two overlapped rigid blocks, under the assumptions of infinite compressive strength for blocks and no-tension and frictional behaviour for contact. The comparisons show that the predicted non-linear yield domain agrees well with the observed experimental results, while the linear approximation was too conservative. A proposed bi-linear approximation reduces the average percentage difference between experimental and predicted shear forces from $21.4 \%$ to $8.7 \%$ with respect to the linear one. This agreement validates the efficacy of the bilinearized yield domain in order to be used in 3D limit analysis formulations.

\section{Acknowledgement}

The authors acknowledge the sponsorship of the Italian Civil Protection, through the RELUIS Project - Line: Masonry Structures (2015).

\section{References}

[1] Casapulla, C., Frictional strength of out-of-plane loaded masonry walls. Proc. of the 9th Nat. Conf. on Seismic Engineering in Italy, Torino (Italy), pp. 1-12, 1999 (in Italian).

[2] Casapulla C., Dry rigid block masonry. Safe solutions in presence of Coulomb friction. Proc. of the 7th Int. Conf. on Structural Studies, Repairs and Maintenance of Historical Buildings, ed. C.A. Brebbia, WITpress: Southampton (UK), pp. 251-261, 2001.

[3] Casapulla, C., Lower and upper bounds in closed form for out-of-plane strength of masonry structures with frictional resistances. Proc. of the 6th Int. Conf. on Structural Analysis of Historical Constructions, eds. D. D’Ayala \& E. Fodde, Taylor \& Francis Group: London (UK), vol. 2, pp. 1191-1198, 2008. 
[4] Casapulla, C., Portioli, F., Maione, A. \& Landolfo, R., A macro-block model for in-plane loaded masonry walls with non-associative Coulomb friction. Meccanica, 48(9), pp. 2107-2126, 2013.

[5] Casapulla, C., Cascini, L., Portioli, F. \& Landolfo, R., 3D macro and microblock models for limit analysis of out-of-plane loaded masonry walls with non-associative Coulomb friction. Meccanica, 49(7), pp. 1653-1678, 2014.

[6] Lourenço, P.B., Oliveira, D.V., Roca, P. \& Orduña, A., Dry Joint Stone Masonry Walls Subjected to In-Plane Combined Loading. Journal of Structural Engineering-ASCE, 131(11), pp. 1665-1673, 2005.

[7] Mihai, L.A., A fixed-point approach to the limit load analysis of multibody structures with Coulomb friction. Computers \& Structures, 88, pp. 859-869, 2010.

[8] Sassu, M., Andreini, M., Casapulla, C. \& De Falco, A., Archaeological consolidation of UNESCO masonry structures in Oman: the Sumhuram Citadel of Khor Rori and the Al-Balid Fortress. International Journal of Architectural Heritage, 7(4), pp. 339-374, 2013.

[9] Tran-Cao, T., Collapse analysis of block structures in frictional contact, PhD Thesis, The University of New South Wales, Sydney (Australia), 2009.

[10] Restrepo-Vélez, L.F., Magenes, G. \& Griffith, M.C., Dry Stone Masonry Walls in Bending-Part I: Static Tests. International Journal of Architectural Heritage, 8(1), pp. 1-28, 2014.

[11] Begg, D.W. \& Fishwick, R.J., Numerical analysis of rigid block structures including sliding. Proc. of the 3rd Int. Symp. on Computer Methods in Structural Masonry, eds. J. Middleton \& G.N. Pande, Portugal, pp. 1771783, 1995.

[12] Ferris, M. \& Tin-Loi, F., Limit analysis of frictional block assemblies as a mathematical program with complementarity constraints. International Journal of Mechanical Science, 43, pp. 209-224, 2001.

[13] Gilbert, M., Casapulla, C. \& Ahmed, H.M., Limit analysis of masonry block structures with non-associative frictional joints using linear programming. Computers \& Structures, 84(13-14), 873-887, 2006.

[14] Orduña, A. \& Lourenço, P.B., Three-dimensional limit analysis of rigid blocks assemblages. Part I: torsion failure on frictional joints and limit analysis formulation. International Journal of Solids and Structures, 42(1819), pp. 5140-5160, 2005.

[15] Portioli, F., Casapulla, C., Cascini, L., D’Aniello, M. \& Landolfo, R., Limit analysis by linear programming of 3D masonry structures with associative friction laws and torsion interaction effects. Archive of Applied Mechanics, 83(10), pp. 1415-1438, 2013.

[16] Portioli, F., Casapulla, C., Gilbert, M. \& Cascini, L., Limit analysis of 3D masonry block structures with non-associative frictional joints using cone programming. Computers \& Structures, 143, pp. 108-121, 2014.

[17] Portioli, F., Cascini, L., Casapulla, C. \& D'Aniello, M., Limit analysis of masonry walls by rigid block modelling with cracking units and cohesive joints using linear programming. Engineering Structures, 57, pp. 232-247, 2013. 
[18] Kooharian, A., Limit analysis of voussoir (segmental) and concrete arches. ACI Materials Journal, 49(12), pp. 317-328, 1952.

[19] Drucker, D.C., Coulomb friction, plasticity and limit loads. Journal of Applied Mechanics, 21(1), pp. 71-74, 1954.

[20] Heyman, J., The stone skeleton. International Journal of Solids and Structures, 2, pp. 249-279, 1966.

[21] Livesley, R.K., A computational model for the limit analysis of threedimensional masonry structures. Meccanica, 27(3), pp. 161-172, 1992.

[22] Casapulla, C. \& D'Ayala, D., Lower bound approach to the limit analysis of 3D vaulted block masonry structures. Proc. of the 5th Int. Symp. on Computer Methods in Structural Masonry, eds. T.G. Hughes \& G.N. Pande, Swansea (UK), pp. 28-36, 2001.

[23] Atkinson, R.H., Amadei, B.P., Saeb, S. \& Sture, S., Response of masonry and joints in direct shear. Journal of Structural Engineering-ASCE, 115(9), pp. 2276-2296, 1989.

[24] Lourenço, P.B. \& Ramos, L.F., Characterization of cyclic behaviour of dry masonry joints. Journal of Structural Engineering-ASCE, 130(5), pp. 779786, 2004.

[25] CEN EN 1052-3. European norm for methods of test for masonry - Part 3: Determination of initial shear strength, 2002.

[26] Casapulla, C. \& Portioli, F., Experimental and analytical investigation on the frictional contact behaviour of 3D masonry block assemblages. Construction and Building Materials, 78, pp. 126-143, 2015.

[27] Casapulla, C. \& Portioli, F., Experimental tests on the limit states of dryjointed tuff blocks, Materials \& Structures, DOI 10.1617/s11527-015-05363, pp. 1-17, 2015.

[28] Feeny, B., Guran, A., Hinrichs, N. \& Popp, K., A historical review on dry friction and stick-slip phenomena. Applied Mechanics Reviews, 51(5), pp. 321-341, 1998. 